\title{
Profile of New Leprosy Cases Attending a South Indian Referral Hospital in 2011-2012
}

\author{
Ramesh Marne Bhat and Prakash Chaitra \\ Department of Dermatology, Father Muller Medical College, Mangalore, Karnataka 575002, India \\ Correspondence should be addressed to Prakash Chaitra; chaitraprakash.plus@gmail.com
}

Received 4 December 2012; Accepted 28 December 2012

Academic Editors: W. Hu and S. Munga

Copyright (c) 2013 R. M. Bhat and P. Chaitra. This is an open access article distributed under the Creative Commons Attribution License, which permits unrestricted use, distribution, and reproduction in any medium, provided the original work is properly cited.

Background. Leprosy, a disabling infectious disease, is a major public health problem in some regions, requiring knowledge of its epidemiological variations so that strategies for case detection and disease control can be subsidized. Objectives. This study aims to evaluate the clinical and epidemiological profiles of leprosy patients attending a referral hospital in South India between 2011 and 2012. Methods. Medical records of newly diagnosed leprosy cases between April 2011 and March 2012 were analysed at the Department of Dermatology, Venereology and Leprosy, Father Muller Medical College Hospital, Mangalore, India. Data were obtained using a specific questionnaire and entered into the database system. Results. Adult males outnumbered females in our study. Detection rate among women and children under 15 years seems to be on the rise. Multibacillary leprosy was more frequent among the new cases with borderline tuberculoid as the predominant type, although smear positivity was seen in less than half of these clinical multibacillary cases. A higher occurrence of lepra reactions, neuritis, and deformities at the time of diagnosis was observed. Conclusion. The results of this study point to a high circulation of lepra bacilli in the community in the "elimination era" and also highlight the need for early diagnosis and appropriate treatment at the field level to prevent spread of bacilli and development of disabilities.

\section{Introduction}

Leprosy is one of those few chronic infectious diseases that are associated with serious physical and functional disabilities affecting the skin and peripheral nerves. Mycobacterium leprae, the causative organism of this malady, is transmitted by droplet spread which is facilitated by close contact. Although leprosy was the first infectious disease to have its etiological agent discovered, it still remains a disease of public health concern because of the case load and the social stigma attached to the disease [1].

With the advent of multidrug therapy (MDT), the prevalence and incidence of the disease has drastically reduced. Compared to more than 5 million cases diagnosed in the year 1990, only 244,796 new cases of leprosy were detected globally in the year 2009 [2]. Among the African and Southeast Asian countries that report the highest numbers, India leads the list by contributing the majority of the cases. This situation is deplorable, considering the fact that on
January 30, 2006, India announced the elimination of leprosy at the national level [3]. About 127,295 new cases are still detected at the end of the year 2011 in India with more than $10 \%$ child cases, indicating active transmission of leprosy in Indian communities [4].

The epidemiology of leprosy in relation to its geographical distribution remains somewhat unclear. The main historically endemic areas in the world have tropical climate with high temperatures and rainfall; however, leprosy has also presented high incidences in temperate and cold regions [5]. Despite the prevalence rate being less than 1 case per 10,000 population, Southern part of India seems to report a large number of new cases probably owing to industrialization and migration. Based on this scenario, this study aims to describe the epidemiological and clinical profiles of newly detected leprosy in a Mangalorean referral hospital in the period ranging from 2011 to 2012, in order to help define strategies in control programmes. 
TABLE 1: Distribution of multibacillary and paucibacillary leprosy cases among adults and children.

\begin{tabular}{|c|c|c|c|c|c|c|c|c|c|c|c|c|c|c|c|c|c|}
\hline \multicolumn{18}{|c|}{ New cases detected $(n=46)$} \\
\hline \multicolumn{6}{|c|}{ Male } & \multicolumn{6}{|c|}{ Female } & \multicolumn{6}{|c|}{ Children $<15$ years } \\
\hline \multicolumn{2}{|c|}{$\mathrm{MB}$} & \multicolumn{2}{|c|}{$\mathrm{PB}$} & \multicolumn{2}{|c|}{ Total } & \multicolumn{2}{|c|}{ MB } & \multicolumn{2}{|c|}{$\mathrm{PB}$} & \multicolumn{2}{|c|}{ Total } & \multicolumn{2}{|c|}{ MB } & \multicolumn{2}{|c|}{$\mathrm{PB}$} & \multicolumn{2}{|c|}{ Total } \\
\hline No. & $\%$ & No. & $\%$ & No. & $\%$ & No. & $\%$ & No. & $\%$ & No. & $\%$ & No. & $\%$ & No. & $\%$ & No. & $\%$ \\
\hline 16 & 64.00 & 9 & 42.86 & 25 & 54.35 & 9 & 36.00 & 12 & 57.14 & 21 & 45.65 & 0 & 0.00 & 7 & 15.22 & 7 & 15.22 \\
\hline
\end{tabular}

\section{Materials and Methods}

This is a descriptive, observational, and retrospective study in which consolidated data on leprosy were analyzed. Patient data were obtained from the medical records of the Department of Dermatology, Venereology and Leprosy, Father Muller Medical College Hospital, Mangalore, India. Health records of 55 leprosy cases who commenced WHO MDT between April 2011 and March 2012 were analysed. Nine out of 55 cases who had history suggestive of antileprosy treatment in the past were excluded from the study. Data recorded in the patients' profiles at the time of diagnosis were retrieved using a specific questionnaire, and the collected data is then entered into the database system.

The patient data concerned the following variables at the time of diagnosis: new cases by sex and age, history of contact with leprosy case, clinical classification, presence of nerve involvement in the form of thickening and/or tenderness, presence of reaction and disability, and smear positivity from the routine sites. The data were processed using Microsoft Office Excel 2007 in the construction of tables.

\section{Results}

Of the 55 cases of leprosy who commenced treatment in this period, 46 (83.63\%) were newly diagnosed cases. Among the new cases, $25(54.35 \%)$ were multibacillary (MB), 21 (45.65\%) were females, 7 (15.22\%) were children, 8 (34.78\%) had visible or grade- 2 deformities, and 15 (65.22\%) had grade-1 disability. Borderline tuberculoid leprosy (34.78\%) was the most common type at the time of diagnosis followed by tuberculoid leprosy (28.26\%). Pure neural type of Hansen's disease was least encountered (2.17\%). Nerve involvement in the form of thickened nerves was documented in 35 (76.01\%) cases, while evidence of neuritis was found in $15(32.61 \%)$ of the cases. Lepra reaction was present in $16(34.78 \%)$ at the time of presentation; occurrence of type 1 reaction (26.09\%) was most frequent compared to type 2 reaction (8.7\%) among the new cases. Only $44 \%$ of the multibacillary and none of the paucibacillary $(\mathrm{PB})$ cases were smear positive. Positive contact history was present only in $8(17.39 \%)$ of the patients.

\section{Discussion}

Leprosy, also known as Hansen's disease, is a chronic infectious disease which is nonfatal, yet one of the most common causes of nontraumatic peripheral neuropathy worldwide. Mycobacterium leprae, the causative agent of leprosy, was discovered by G. H. Armauer Hansen in Norway in 1873,
TABLE 2: Distribution of new cases of leprosy according to age group.

\begin{tabular}{lc}
\hline & Age distribution $(n=46)$ \\
Age in years & No. $(\%)$ \\
\hline$<15$ & $7(15.22 \%)$ \\
$16-35$ & $14(30.43 \%)$ \\
$36-50$ & $19(41.31 \%)$ \\
$>50$ & $6(13.04 \%)$ \\
\hline
\end{tabular}

making it the first bacterium to be identified as causing disease in humans [6]. It is an intracellular acid-fast bacillus with an affinity for Schwann cells and skin macrophages. Man is considered the only natural reservoir of the bacillus, although there have been reports of naturally infected wild animals (armadillos and monkeys). Patients with the multibacillary forms of the disease are considered the principal source of infection; nevertheless, the role of paucibacillary forms in the chain of transmission has already been demonstrated [7].

Multibacillary cases were more common (54.35\%) among the new cases attending the out-patient department of our hospital in comparison with the paucibacillary cases. Males outnumbered females in our study group in concordance with Sousa et al. [8] (Table 1). The reason for this is generally considered to be the risk of exposure; however, the increasing number of cases among females is worthy of mention. Although some studies show that leprosy affects more men than women, there are exceptions such as in the study conducted by Gomes et al. where females outnumbered males [9]. This small increase in the rates may be the result of an increase in the number of infected women or may be due to a more effective identification of these carriers. An improvement in the access of women to healthcare services and the fact that women are more concerned with their self-image than men could explain this increase in the identification of female cases.

Our study shows that leprosy affects predominantly young adults rather than children (Table 2). However, the detection rate in children under the age of 15 years continues to be high as witnessed in our study in agreement with the previous reports $[8,10]$. The maintenance of high endemic levels of leprosy suggests that children may be contacts of cases not yet detected by the healthcare system. In conditions of high transmissibility and early exposure to the bacillus, the probability of becoming ill increases; therefore, detection in this age group can be taken as an indicator of the greater severity of the endemic state of the disease. Amador et al. reported that in children under five years of age, leprosy may be potentially disabling due to the young age at which the 
TABLE 3: Contact history in newly detected leprosy cases.

\begin{tabular}{lccc}
\hline \multicolumn{4}{c}{ History of contact with leprosy case $(n=46)$} \\
Present & $\%$ & No. & $\%$ \\
\hline 8 & $17.39 \%$ & 38 & 82.61 \\
\hline
\end{tabular}

TABLE 4: Distribution of new leprosy cases into clinical types.

\begin{tabular}{lc}
\hline \multicolumn{2}{c}{ Classification of new leprosy cases $(n=46)$} \\
Type & No. $(\%)$ \\
\hline Indeterminate & $2(4.35)$ \\
Tuberculoid & $13(28.26)$ \\
Borderline tuberculoid & $16(34.78)$ \\
Mid-borderline & $6(13.04)$ \\
Borderline lepromatous & $4(8.70)$ \\
Lepromatous & $2(4.35)$ \\
Pure neural & $1(2.17)$ \\
Histoid & $2(4.35)$ \\
\hline
\end{tabular}

TABLE 5: Lepra reaction in new cases of leprosy.

\begin{tabular}{lccccc}
\hline \multicolumn{3}{c}{ Reaction among new cases at the time of presentation $(n=46)$} \\
Type 1 & \multicolumn{2}{c}{ Type 2} & \multicolumn{3}{c}{ Total } \\
No. & $\%$ & No. & $\%$ & No. & $\%$ \\
\hline 12 & 26.09 & 4 & 8.70 & 16 & 34.78 \\
\hline
\end{tabular}

disease was contracted and the possibility of determining deformities, although the occurrence of severe disabilities in children is uncommon [11]. However, there was no case of child less than 5 years of age detected during our study period. On the other hand, the number of cases was found to increase with age, with the disease affecting principally the economically active population of $16-50$ years of age. This indicates that the economically active population is the segment most affected by leprosy, which may exert a negative impact on the economy of the state, since this segment of the population may go on to develop disabilities, lesions, or leprosy reactional states that would remove them from productive activity and generate high social costs [12].

Close contact with leprosy affected persons aids in development of the disease in susceptible individuals, 8 (17.39\%), though not in all contacts as observed in our study (Table 3 ).

Sixteen $(34.78 \%)$ patients were in reactional state at the time of diagnosis. Type 1 lepra reaction was more common (26.09\%) probably owing to the high proportion of borderline cases in the study group (Tables 4 and 5).

Nerve thickening and neuritis were seen in 35 (76.01\%) and $15(32.61 \%)$ of new cases, respectively (Table 6). Nerve damage causes sensitivity and motor alterations, leading to various degrees of physical disability that may affect patients' social and economic life, resulting in their stigmatization and discrimination [13].

Deformities and physical disabilities are the principal problem in leprosy, the percentage of patients with physical disabilities being an indicator of the impact of the disease
TABLE 6: Skin and nerve involvement in new cases of leprosy.

\begin{tabular}{lccccc}
\hline & \multicolumn{3}{c}{ Nerve involvement among new cases } & \multicolumn{2}{c}{$(n=46)$} \\
Skin lesions alone & \multicolumn{2}{c}{$\begin{array}{l}\text { Skin lesions with } \\
\text { thickened nerves }\end{array}$} & \multicolumn{2}{c}{$\begin{array}{c}\text { Nerve tenderness } \\
\text { alone }\end{array}$} \\
No. & $\%$ & No. & $\%$ & No. & $\%$ \\
\hline 11 & 23.91 & 35 & 76.01 & 15 & 32.61 \\
\hline
\end{tabular}

TABLE 7: Disability in new leprosy cases.

\begin{tabular}{lccccc}
\hline \multicolumn{3}{c}{ Disability among new cases at the time of diagnosis $(n=46)$} \\
Grade-1 & \multicolumn{2}{c}{ Grade-2 } & \multicolumn{2}{c}{ Total } \\
No. & $\%$ & No. & $\%$ & No. & $\%$ \\
\hline 15 & 65.22 & 8 & 34.78 & 23 & 50.00 \\
\hline
\end{tabular}

TABLE 8: Bacteriological smear positivity in new leprosy cases.

\begin{tabular}{lccccc}
\hline \multicolumn{5}{c}{ Smear positivity among new cases } \\
\multicolumn{2}{c}{ MB $(n=25)$} & \multicolumn{2}{c}{$\operatorname{PB}(n=21)$} & \multicolumn{2}{c}{ Total $(n=46)$} \\
No. & $\%$ & No. & $\%$ & No. & $\%$ \\
\hline 11 & 44.00 & 0 & 0.00 & 11 & 23.91 \\
\hline
\end{tabular}

[14]. Half of the newly detected cases had disabilities, 8 (34.78\%) of whom had visible deformity which is a matter of concern as it points towards the deficiencies in early diagnosis (Table 7). This also suggests continued need for referral hospitals for their management and also population-based overall assessment whether actual numbers with deformities have increased or it is peculiar to a tertiary care hospital where the cases with problems may be coming [15].

Only $11(44 \%)$ of the clinical multibacillary cases and none of the clinical paucibacillary cases showed bacteriological smear positivity (Table 8 ). This mirrors the low sensitivity of slit-skin smear in the demonstration of acid-fast bacilli in the body fluid. It also emphasizes the need for a more sensitive procedure such as histopathological examination in smearnegative cases which allows appropriate categorization of the disease for the purpose of treatment [16].

Main limitation of this retrospective study includes the fact that analysis of the prerecorded details of leprosy patients at the time of initial diagnosis is limited and nonexpandable. Categorization into a clinical type was not uniform in all cases subject to lack of adherence to a single classification in clinical practice. Although histopathology was used as a tool for diagnosis in the majority of the cases, details were not analyzed due to nonavailability of this consent-based procedure in all the included study cases which otherwise could have yielded better detection rates.

\section{Conclusion}

The results of this study point to a high circulation of lepra bacilli in the community in the "elimination era." It also highlights the need for early diagnosis and appropriate treatment at the field level to prevent the spread of bacilli and development of disabilities. 


\section{References}

[1] J. Khubchandani, "State of the globe: many challenges of the multifaceted leprosy," Journal of Global Infectious Diseases, vol. 3, pp. 315-316, 2011.

[2] World Health Organization, "Global Leprosy situation 2010," The Weekly Epidemiological Record, vol. 35, pp. 337-348, 2010.

[3] G. P. S. Dhillon, "NLEP-Current situation and strategy during the 11th plan period (2007-2012)," Journal of the Indian Medical Association, vol. 104, no. 12, pp. 671-672, 2006.

[4] “NLEP-Progress report for the year 2011-2012," 2012, http:// www.nlep.nic.in/data.html.

[5] M. C. C. Magalhães and L. I. Rojas, "Time trends of Hansen's disease in Brasil," Revista Brasileira de Epidemiologia, vol. 8, no. 4, pp. 342-355, 2005.

[6] V. Jay, “The legacy of Armauer Hansen," Archives of Pathology and Laboratory Medicine, vol. 124, no. 4, pp. 496-497, 2000.

[7] S. M. B. Durães, L. S. Guedes, M. D. Da Cunha, F. A. M. Cavaliere, and M. L. Wand del Rey de Oliveira, "Study of 20 families with leprosy cases from Duque de Caxias-Rio de Janeiro-Brazil," Anais Brasileiros de Dermatologia, vol. 80, no. 3, pp. S295-S300, 2005.

[8] M. W. Sousa, D. C. Silva, L. R. Carneiro, M. L. Almino, and A. L. Costa, "Epidemiological profile of leprosy in the Brazilian state of Piau? between 2003 and 2008," Anais Brasileiros de Dermatologia, vol. 87, pp. 389-395, 2012.

[9] C. C. D. Gomes, G. O. Penna, M. A. P. Aires, and H. S. Gonçalves, "Clinical and epidemiological profile of patients diagnosed with leprosy in a reference center in the notheast of Brazil," Anais Brasileiros de Dermatologia, vol. 80, supplement 3, pp. S283-S288, 2005.

[10] E. V. E. Pereira, H. A. S. Machado, C. H. M. Ramos, L. T. Nogueira, and L. A. N. Lima, "Epidemiologic profile of the leprosy of the city of Teresina, in the period of 2001-2008," Anais Brasileiros de Dermatologia, vol. 86, no. 2, pp. 235-240, 2011.

[11] M. P. S. C. Amador, V. R. S. Barros, P. J. B. S. Albuquerque, M. I. F. Buna, and J. M. Campos, "Hanseníase na infância no município de Curionópolis-sudeste do Estado do Pará relato de caso," Hansenologia Internationalis, vol. 26, no. 2, pp. 121-125, 2001.

[12] S. S. C. Miranzi, L. H. M. Pereira, and A. A. Nunes, "Epidemiological profile of leprosy in a brazilian municipality between 2000 and 2006," Revista da Sociedade Brasileira de Medicina Tropical, vol. 43, no. 1, pp. 62-67, 2010.

[13] I. M. B. Goulart, G. L. Arbex, M. H. Carneiro, M. S. Rodrigues, and R. Gadia, "Adverse effects of multidrug therapy in leprosy patients: a five-year survey at a Health Center of the Federal University of Uberlândia," Revista da Sociedade Brasileira de Medicina Tropical, vol. 35, no. 5, pp. 453-460, 2002.

[14] M. Pedroso, S. Oliveira, R. Bacarlli, P. C. T. Vieira, and A. Gonçalves, "Incapacidades físicas em hanseníase: estudo multicêntrico da realidade brasileira," Anais Brasileiros de Dermatologia, vol. 64, no. 6, pp. 301-306, 1989.

[15] S. Daniel, S. Arunthathi, and P. S. S. S. Rao, "Impact of integration on the profile of newly diagnosed leprosy patients attending a referral hospital in South India," Indian Journal of Leprosy, vol. 81, no. 2, pp. 69-74, 2009.

[16] P. Bhushan, K. Sardana, R. Koranne, M. Choudhary, and P. Manjul, "Diagnosing multibacillary leprosy: a comparative evaluation of diagnostic accuracy of slit-skin smear, bacterial index of granuloma and WHO operational classification," Indian Journal of Dermatology, Venereology and Leprology, vol. 74 , no. 4 , pp. 322-326, 2008. 


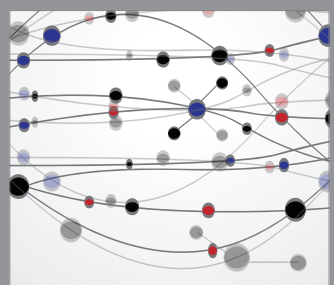

The Scientific World Journal
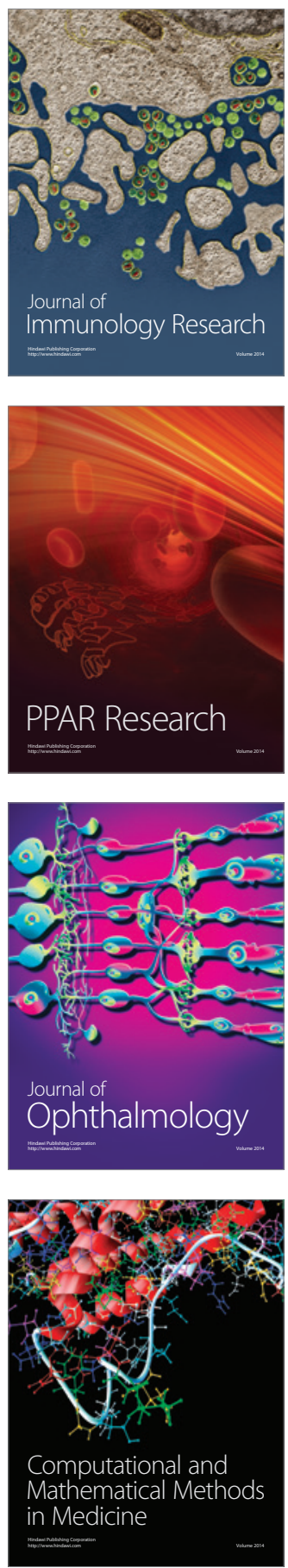

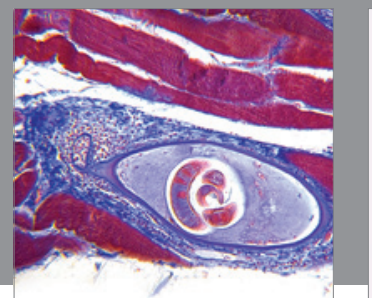

Gastroenterology

Research and Practice
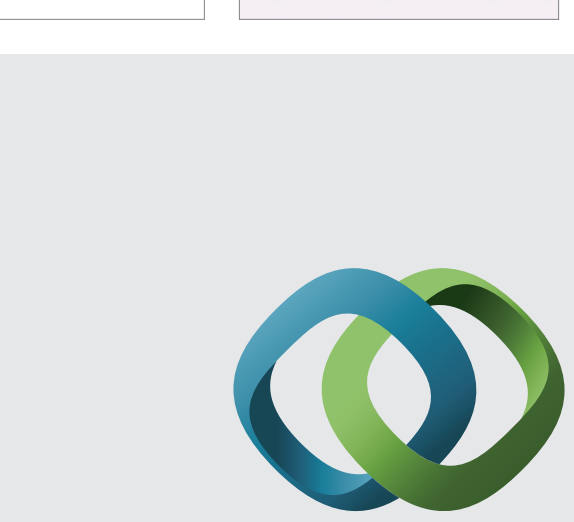

\section{Hindawi}

Submit your manuscripts at

http://www.hindawi.com
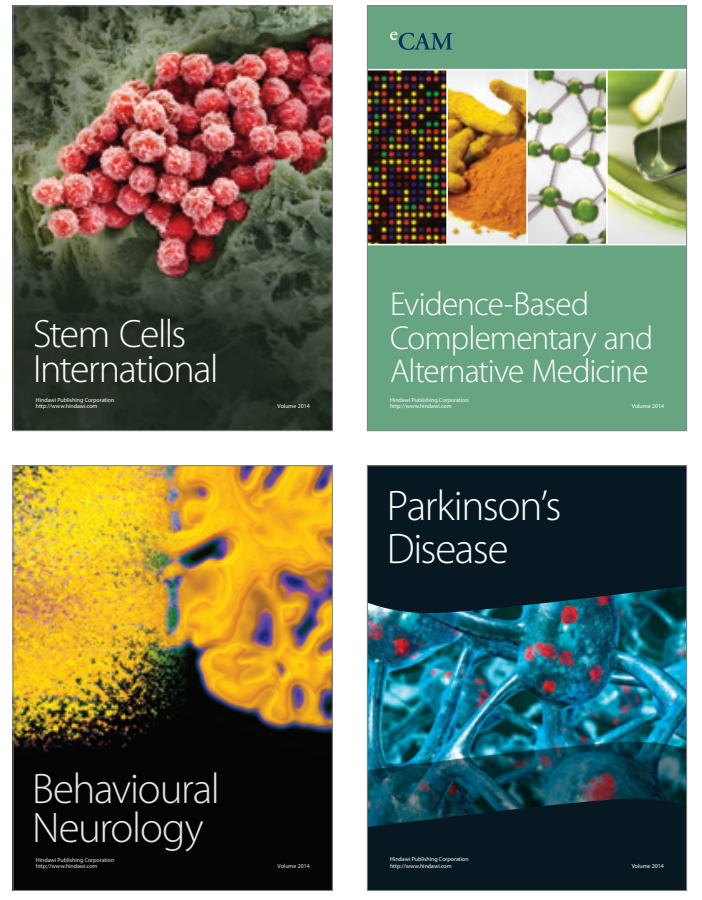
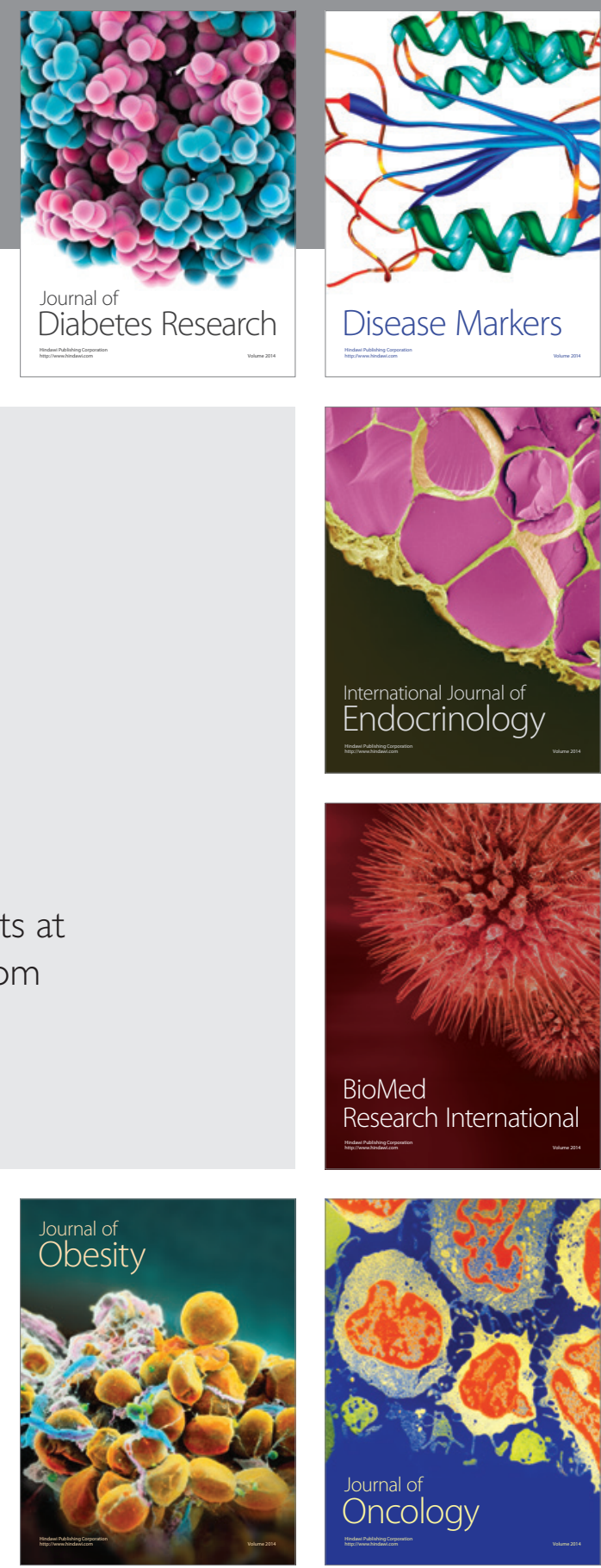

Disease Markers
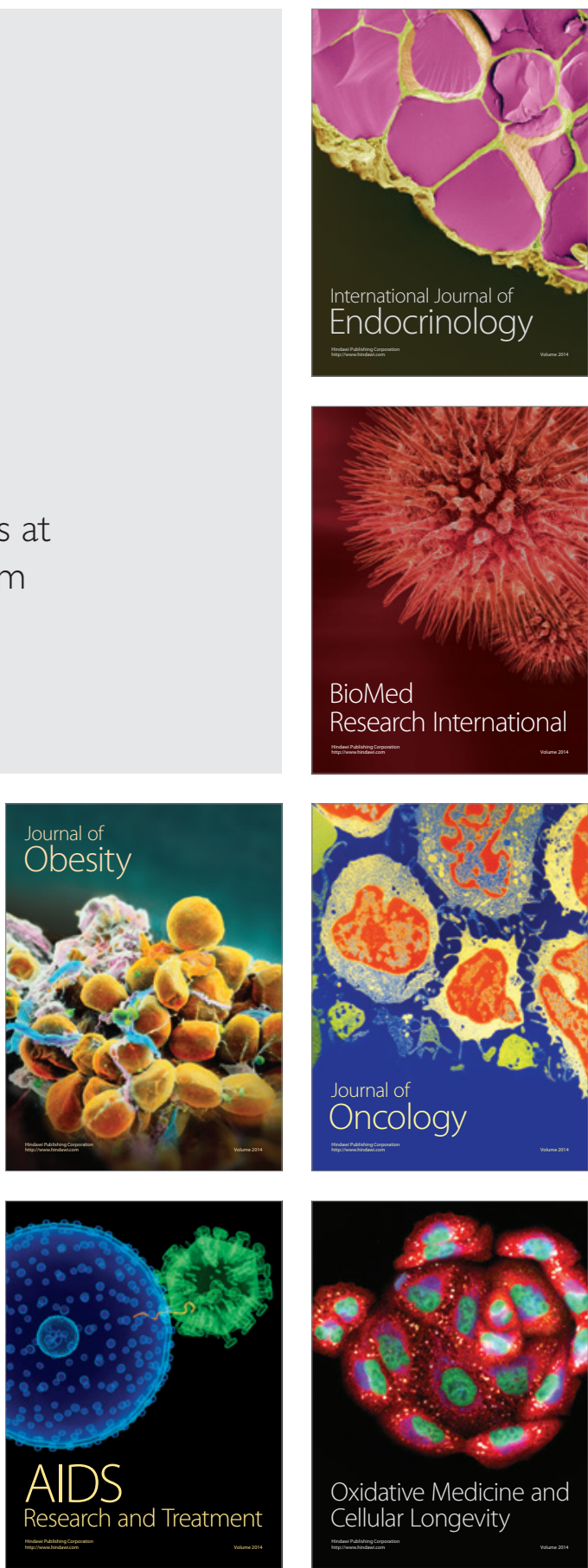